BLS 33, No 1 2007. DOI: http://dx.doi.org/10.3765/bls.v33i1.3542

(published by the Berkeley Linguistics Society and the Linguistic Society of America)

\title{
Phonological Structure in Syllabification: Evidence from Dyslexia
}

\author{
PATRICIA SCHNEIDER-ZIOGA \\ California State University, Fullerton
}

\author{
FUSA KATADA \\ Waseda University
}

\section{Introduction}

Developmental dyslexia is believed to involve deficits in phonological awareness (Goswami 2003). Researchers have argued this inability leads to weak phonological representations of words in the mental lexicon. This suggests the main problem for dyslexic people lies in their inability to remain faithful to adult forms. Contra the mainstream view, we argue that the core problem does not lie in phonemic awareness. Instead we argue the core problem lies in a disturbance of temporal-spatial ordering abilities evinced in lexical semantic and atypical prosodic development. In particular we suggest the atypical prosodic development leads the person with dyslexia not to exploit the unit rime in reading. The absence of the construct rime is highly problematic because accurate and efficient acquisition of reading in English requires reference to rime: the pronunciation of vowel graphemes in this orthographically opaque language is most predictable in the context of the coda grapheme(s) (Treiman et al 1995). We propose that the metrical construct FOOT has not emerged and therefore a constraint such as FOOT-BINARY does not drive syllabification of post vocalic consonants as codas. Instead, the person with dyslexia is free to syllabify post vocalic consonants as onsets. Our analysis implies the notion rime is not available in the initial state of language. We locate the underlying disturbance in dyslexia in the domain of temporal-spatial organization and observe that this affects the construction of the rime and, thus, the hierarchical structure of the syllable.

\section{Background}

\subsection{Developmental Dyslexia: Its Characteristics and Its Indicators}

Developmental dyslexia (henceforth simply dyslexia), as opposed to acquired dyslexia, is characterized by a failure to reach age appropriate reading abilities despite adequate intelligence, educational opportunities, and socioeconomic possibilities, and in the absence of any cognitive problems such as poor vision or obvious brain damage (Vellutino 1979).

Some of the commonly found indicators of the phonological deficit associated with dyslexia are: (a) rapid naming problems as established by 
behavior in RAN (Rapid Automatic Naming) tasks; (b) verbal short term memory difficulties; (c) difficulties in spoonerism tasks.

In a RAN task, a subject is presented with a list of digits, letters of the alphabet, or pictures of common objects and is required to name them as rapidly as possible. Problems with this task indicate difficulties in lexical access or lexical retrieval. The clearest cases of purely phonological problems in verbal short term memory tasks are ones where the subject is auditorily presented with, for example, three phonologically plausible but semantically empty nonwords (such as: tegdep, retway, and mollup) and asked to recall them. In a spoonerism task, a subject is presented with two words, for instance, the words bat and pin, and asked to exchange the initial sounds of both words. In the example, the target spoonerism would be pat bin. Often the presentation is accompanied by matching pictures so as not to also test the subject's memory of the presented words. Problems with spoonerism tasks are interpreted as difficulties segmenting a word into smaller phonological units.

\subsection{Phonemic Awareness and Orthographic Opacity versus Transparency}

The potential relevance of phonemic awareness to reading was first pointed out by the research group at Haskins in the late 1970's. They noted that there is a particular segmental level, the phonemic one, which seems critical to reading an alphabetic language. This is because an alphabetic language is based on the alphabetic principle, which is the important insight that a grapheme, a meaningless graphic symbol, can be used as a symbol for another meaningless abstract unit, a phoneme. The Haskins group suggested that the phoneme is particularly difficult for conscious access because it is obscured by coarticulation. Their slogan was "reading is difficult because listening is easy." That is, phonemes are not perceptually real, but they must be hypothesized for successful reading.

Many studies have been able to duplicate the findings that phonemic awareness is impaired in dyslexic readers. However, the subjects of these studies are limited to disabled readers of English only. As research has begun to include work on alphabetic languages other than English, it has become clear that impairments in phonemic awareness are most apparent in alphabetic languages that also have the property of being orthographically opaque. To be orthographically opaque means that there is not a consistent mapping between grapheme and phoneme. The opacity might express itself in an inconsistency such that a particular grapheme is pronounced one way in some words, but a different way in other words. Representative of such a language is English, as opposed to orthographically transparent languages such as Spanish, Italian, German, and Dutch. As table (1) shows, especially vowel graphemes are unpredictable in their pronunciation in English (Treiman et al 1995; Kessler and Treiman 1997), whereas in German there is approximately a one to one mapping between grapheme and phoneme, as table (2) shows. 
(1) Opacity of English orthography: graphemes vs. phonemes

\begin{tabular}{|c|c|c|}
\hline graphemes & in words spelled & phonemes (in IPA) \\
\hline $\mathrm{a}$ & father, fat, staple & /faðı/, /foet/, /stepl/ \\
\hline e & bet, be, Bert & $/ \mathrm{b} c \mathrm{t} /, / \mathrm{bi} /, / \mathrm{b}_{1 \mathrm{t}} \mathrm{t} /$ \\
\hline $\mathrm{i}$ & bird, pint, hint & /bard/, /pajnt/, /hrnt/ \\
\hline ou & should, shoulder, foul & $/ \int u \mathrm{~d} /, / \int o l d \mathrm{I} /, / \mathrm{f} a w \mathrm{l} /$ \\
\hline
\end{tabular}

(2)

Transparency of German orthography: graphemes to phonemes

\begin{tabular}{|c|c|c|}
\hline graphemes & in words spelled & phonemes (in IPA) \\
\hline $\mathrm{a}$ & Vater, an, nah & /fater/, /an/, /na:/ \\
\hline e & ersten, Ecke, Knecht & $/ \varepsilon \operatorname{rst} \varepsilon \mathrm{n} /, / \varepsilon \mathrm{k} \varepsilon /, / \mathrm{kn} \varepsilon c_{c} \mathrm{t} /$ \\
\hline $\mathrm{i}$ & Ich, finden Birgit & /Iç/,/ffnden/, /bIrgIt/ \\
\hline $\mathrm{au}$ & $\begin{array}{l}\text { Glauben, August, } \\
\text { Traum }\end{array}$ & $\begin{array}{l}\text { /glawben/, /awgust/, } \\
\text { /trawm/ }\end{array}$ \\
\hline
\end{tabular}

Disabled readers of orthographically transparent languages do not exhibit long lasting problems with phonemic awareness, though they share with dyslexic readers of orthographically opaque languages other problems such as slow reading speed and difficulties with RAN tasks.

\subsection{Orthographic Opacity and the Unit Rime}

Turning to English, the most opaque orthographic system of all alphabetic languages, the statistical analyses carried out by Kessler and Treiman (1997) reveal a strong tendency of English orthography to be rime-based: the coda provides more useful information about the possible pronunciation of the vowel grapheme than the onset. Treiman et al (1995) documents VC as a more predictable environment for orthographic pronunciation than $\mathrm{CV}$. For example, the digraph $e a$ is almost always pronounced $[\varepsilon]$ before $d$ (the orthographic rime ead as in bread, tread, head, and dead), and as [i] before $p$ (the orthographic rime eap as in heap, leap, and cheap). On the other hand, onset graphemes do not offer a clue as we can see by the varying CV graphemes of these examples.

This means that in order to successfully read English, not only must one know the various possible mappings of the vowel grapheme to its appropriate phoneme, but, more importantly, the reader must exploit the unit rime in the process in order to be able to take into account the maximally informative context for accurate pronunciation of the vowel grapheme. In orthographically transparent languages such as German, it is not necessary to exploit the unit rime in reading that language since the mapping between grapheme and phoneme is consistent.

An important finding in this respect is that of Goswami $(1999,2001)$, who in her study of English speaking/reading children presents experimental evidence that rimes are important for reading (see also Wise, Olson, and Treiman 1990). She argues that beginning readers strongly benefit from exploiting the unit rime to read analogically. Other studies confirm this position. For example, in 


\section{Patricia Schneider-Zioga and Fusa Katada}

experiments conducted by Wise, Olson, and Treiman (1990), onset-rime segmentation of written words proved more helpful than postvowel segmentation in short-term learning of the words for beginning readers, as in (3).

Types of segmentation
\begin{tabular}{|l|l|l|}
\hline words & $\begin{array}{l}\text { onset-rime } \\
\text { segmentation }\end{array}$ & $\begin{array}{l}\text { postvowel } \\
\text { segmentation }\end{array}$ \\
\hline ship & sh.ip & shi.p \\
\hline big & b.ig & bi.g \\
\hline
\end{tabular}

Moreover, Duncan et al. (1997) finds that poor rhymers were poor readers and good rhymers were good readers. These facts not only indicate that efficient readers, at least in some point early in their reading development, make use of the construct rime, they also suggest that a disturbance in the ability to construct rime would severely impact the reading of English, at least during early development.

\section{Our Case Study: CV as Fundamental Unit}

\subsection{Brief Profile of Our Case}

We undertook a case study of an English-speaking girl with dyslexia, born in 1988, henceforth called Tara, a pseudonym. Tara's language development seemed completely normal. However, Tara's mother was concerned about Tara's slow acquisition of reading and spelling and had her tested on a number of psychometric tests at relevant stages in her development. She demonstrated well above average language abilities in various tests including forward digit repetition, the Peabody Picture Vocabulary test, Boston Diagnostic Aphasic Examination; Tara's IQ score was 131. Nonetheless, Tara had great difficulties in learning to read, spell, and write. Tara looked predictably atypical in one language measure: rapid naming, a problem with which consistently correlates with dyslexia.

The next two subsections show a striking contrast in Tara's reading: the presence of onsets versus lack of codas. Her reading can be characterized as involving an overproduction of $C V$ units and a decided lack of VC units, leading to highly inefficient decoding. Our observations are concerned with words that Tara does not already know how to read. The words she reads for these observations are nonsense words, Latin, or vocabulary items that are at a very advanced reading level. Since these words are not already in Tara's reading vocabulary, she must use a phonological route to arrive at the correct pronunciation. All words were presented to her as individual words on a reading list, and therefore she could not use contextual clues to arrive at a plausible pronunciation.

\subsection{Observation 1: The Avoidance of Coda except Word-Finally}




\section{Phonological Structure in Syllabification}

Our first observation is that Tara avoids pronouncing codas in all positions except word finally, an exception to which we return in section 3.4. In all of the examples in (4), Tara pronounces the codas as onsets. She achieves this either by epenthesizing a vowel immediately after the word internal coda (4a, b, c, and d), or by metathesizing a vowel from a nearby vowel digraph so that a vowel follows the coda $(4 \mathrm{e}, \mathrm{f}, \mathrm{g})$, or by simply deleting a word-internal coda (4h).

Avoidance of Coda via Epenthesis, Metathesis, or Deletion
\begin{tabular}{|l|l|l|l|}
\hline & presented word & Tara's pronunciation & process \\
\hline \hline (a) & regatleb & [ri.'ga.ti.leb] & epenthesis \\
\hline (b) & bailesbud & [be.'li.sI.bəd] & epenthesis \\
\hline \hline (c) & besaubgant & [bi.'sa.bI.gænt & epenthesis \\
\hline (d) & aipcid & ['e.pI.sId] & epenthesis \\
\hline (e) & maudlin & ['ma.du.lin] & metathesis \\
\hline (f) & leegtab & [le.'ga.tə.bə] & metathesis \\
\hline (g) & weipgan & ['wi.pr.gæn] & metathesis \\
\hline (h) & wepgad & ['we.gæd] & deletion \\
\hline
\end{tabular}

\subsection{Observation 2: The Presence of Complex Onsets}

By contrast, onsets, including word-internal complex onsets, are intact for Tara.

(5) The presence of complex onsets

\begin{tabular}{|l|l|l|l|}
\hline & presented word & Tara's pronunciation & complex onsets: \\
\hline \hline (a) & feestary & ['fi.stə.na.ri] & $\mathrm{sC}$ \\
\hline (b) & reastal & ['ri.stəl] & $\mathrm{sC}$ \\
\hline (c) & toispar & ['toI.spar] & $\mathrm{sC}$ \\
\hline (d) & roipsar & ['roI. spar] & $(p s \rightarrow s p)$ \\
\hline (e) & degatrab & [di.'gæ.træb] & $\mathrm{Cr}$ \\
\hline (f) & tobrawnest & [to.bra.wə.nest], & $\mathrm{Cr}$ \\
\hline \hline (g) & pelaustible & [pla.sI.tə.bl] & $\mathrm{sC} \rightarrow$ səCə \\
\hline
\end{tabular}

In the above examples, we see that if the orthographic sequence $\mathrm{CC}$ occurs wordinternally, several things can happen. Most commonly, if the sequence is a possible onset according to the phonotactics of English, it was able to be pronounced as an onset. In these cases the word internal sequences: $s t, s p$, and $t r$ are mapped as complex onsets and the words are read accurately.

The example in (d) is noteworthy. The word internal sequence is $p s$. The only way to interpret this is as a coda followed by an onset. The observed prohibition on codas word internally would seem to require an epenthesis of a vowel; that is, a $\ldots \mathrm{C}_{1} \mathrm{C}_{2} \ldots$ sequence would be pronounced as $\ldots \mathrm{C}_{1} \mathrm{~V} . \mathrm{C}_{2} \ldots$ 
However, there is another possibility that Tara exploited for this example: the sequence $p s$ can be metathesized to $s p$ and form a licit complex onset: $\mathrm{C}_{1} \mathrm{C}_{2} \rightarrow$ $\mathrm{C}_{2} \mathrm{C}_{1}$.

The example in (f) has two word internal sequences in the orthographic input: $b r$ and $w n$. Tara pronounced the first sequence $b r$ as a complex onset in accordance with the phonotactics of English. The second sequence: wn, which could not be interpreted as a complex onset, was pronounced with an epenthetic vowel: wan in order to avoid pronouncing a coda. The final example $(\mathrm{g})$, where pelaustible maps to [pla.si.to.bl], illustrates that a licit complex onset, the sequence $s t$, can also map as CV.CV. In sum, we see that Tara can have syllables that are more complex than the unmarked CV syllable; however, only complex onsets are possible. Codas appear only in word final position.

\section{Phonology of Dyslexia: The Temporal-Spatial Disordering Hypothesis}

The above discussion introduced and underscored the fact that Tara's reading errors reveal her reliance on CV as a unit of sequential organization of the melody of the words she reads. Now we consider the source of her reliance on this unit. The leading hypothesis in dyslexia research is that there is a problem with phonological awareness and this problem leads to essentially an incomplete or weak representation of the melody of a word (see Goswami 2003 for interesting discussion). We advance the hypothesis that a higher level problem is responsible for Tara's reliance on CV. We suggest that Tara has general temporal-spatial ordering problems and this has repercussions at several levels of the grammar: lexical semantics and metrical phonology.

\subsection{Temporal-Spatial Semantic Difficulties}

First, we note Tara's temporal-spatial difficulties as reflected in her lexical semantics. Tara reports confusion in understanding the meaning of before and after, above and below, and right and left. The following example illustrates a typical error. Here she is using above in a purely relational sense to mean on the other side.

"Mommy, sit above the blanket." (17 years 2 months)

(Meaning: "Mommy sit oriented to the other side of the blanket." i.e., under the blanket)

Tara also reports confusion in understanding the meaning of instructions that state "before X, Y," or "after X, Y." Specifically, she is unsure of which temporal sequence is intended.

\subsection{Auditory and Motor Rhythm Awareness}

There is literature that suggests people with dyslexia have problems with rhythmic awareness. We interpret this problem with rhythmic awareness as a reflex of temporal-spatial ordering problems. Thomson et al (2006) and Goswami 


\section{Phonological Structure in Syllabification}

et al (2002) report that children and adults with developmental dyslexia have difficulties with auditory cues to speech rhythm and stress. Both expressive and receptive abilities seem affected. Also non-linguistic areas are affected such as manual tapping to a metronome, and perception of amplitude modulating tones as having a beat or not. It is known that rhythmic periodicity in speech is related to the onset of vowels in stressed syllables (P-center cue). Researchers suggest that this affects the ability to gain access to segmental organization within syllables.

\subsection{The Temporal-Spatial Ordering Problem and its Metrical Correlate}

We hypothesize that the temporal-spatial ordering problem that is suggested by the difficulties with rhythmic awareness has a metrical correlate. This is because the task of the metrical component of the grammar is to grammatically organize units both temporally and spatially. We propose that Tara's overproduction of CV units is the reflex of a problem with the temporal-spatial ordering of salient items (vowels) versus non-salient items (consonants).

From this perspective, consider the view of articulatory phonology that the onset of a syllable is a co-articulation on the vowel (Goldstein et al, as developed in Vergnaud 2007). Also relevant is the observation that the onset consonant forms a tight unit with a following vowel in the Japanese mora-based system (cf. Katada 1990, Kubozono 1989). Given these views, we can think of the onset then as an autosegment of the vowel:

$$
\begin{aligned}
& \mathrm{C} \\
& \text { I }
\end{aligned}
$$

As an autosegment, there is essentially no ordering decision to make for $\mathrm{CV}$, the $\mathrm{C}$ is part of the salient unit. Therefore, the ordering of $\mathrm{CV}$ is for free. The representation of $\mathrm{CVC}$ under this view must then require a temporal-spatial ordering decision about the order of $\mathrm{CV}$ and $\mathrm{C}$, where the following representation is required for a CVC syllable:

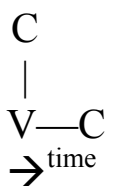

The coda, a nonsalient item which is not a co-articulation of the vowel, cannot as easily be integrated into the syllable and requires a temporal-spatial ordering decision. The ordering must be as in (9) or as in (10):

C C




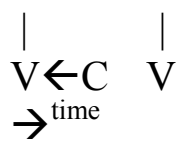

(10)

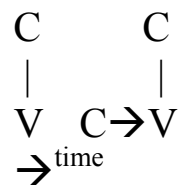

The above scenarios illustrate the problematic aspects of temporal spatial ordering decisions for the ordering of non-salient and salient items. An obvious solution where Tara can avoid any temporal-spatial ordering decision is to interpret a potential coda as the coarticulation of a different syllable, or to delete it altogether. This produces a parse of a multisyllabic word CVC.CV as CV.CV.CV.

\subsection{The Presence of Word-Final Codas}

There is an exception, however, at word margins. As Table (4) shows, Tara appears to have word-final codas, such as (4a) regatleb [re.ga.ti.leb]. The presence of her word-final codas do not necessarily argue for her knowledge of coda. The coda at a right word margin can only be associated with the preceding $\mathrm{V}$, and hence Tara is not faced with a temporal-spatial ordering decision about how to integrate the consonant into the word. Alternatively, we interpret the fact as support for Goad and Brannen (2003), who present phonetic evidence that in English, word final consonants in early stages of child language acquisition are actually syllabified as onsets.

\subsection{The Avoidance of VV Sequences}

Sequences of vowels are also not allowed in Tara's reading; sequences are broken up by intervening C's (11a-f). CV is exceptionally not required at left word margins (11f).

The absence of VV sequences

\begin{tabular}{|l|l|l|}
\hline & presented words & Tara's pronunciation \\
\hline (a) & patior & {$[$ pa.ti.tor $]$} \\
\hline (b) & diurnal & {$[$ du.ri.nal $]$} \\
\hline (c) & deviate & {$[$ de.ly.vet $]$} \\
\hline (d) & scio & {$[$ si.ko $]$} \\
\hline (e) & celo & {$[$ kle.do] $(*[$ kleo] $)$} \\
\hline (f) & aipcid & [e.pi.sid $]$ \\
\hline
\end{tabular}

Here, a temporal-spatial ordering decision has to be made about the two vowelsare they part of a heavy syllable as in (12) or two distinct syllables as in (13)?

$$
\text { C }
$$




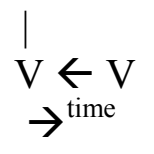

(13)

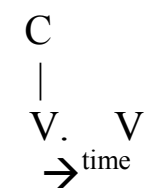

Tara seems to avoid the ordering decision and inserts $\mathrm{C}$ between the two vowels. At the left word margin, there is no ambiguity involving a temporal spatial ordering decision, so V can occur without an onset as in (11f).

\subsection{Proposal}

To account for Tara's overproduction of CV (moraic) units, we propose that she has a less developed syllable structure than a typical reader and we suggest this is because her acquisition is delayed or incomplete. Specifically, we assume that CV is a basic organizing unit of phonological melody. This view is consonant with the fundamental idea of Lowenstamm's (1996) CV only phonology. Because of the absence of the construct rime in Tara's data and its importance in the reading literature, we believe that in typical phonologies the $\mathrm{CV}$ units are organized into a larger unit syllable from which the construct rime can be derived. Furthermore, the development of the unit syllable is the important step that drives efficient reading acquisition.

Specifically, we propose that metrical construct FOOT (at least moraic trochee) is absent for Tara and that this could explain why she has difficulties making the temporal-spatial ordering decision that syllabifies post vocalic C's as codas. Tara has reading difficulty in the orthographically opaque language English which requires a reliance on rime to decode because she lacks the metrical structure required for decoding.

\subsection{Implications to Language Acquisitions}

Parallels with early child language (lack of foot) suggest immature readers and readers with dyslexia will have similar behavior: specifically, also an overreliance on CV. This prediction has been borne out in a study of blending skills in beginning readers (Cassady and Smith 2004) where nascent readers blend CVC words more efficiently as $\mathrm{CV}+\mathrm{C}$ than $\mathrm{C}+\mathrm{VC}$ : eg.: $c a+t$ is preferred to $c+a t$.

Our proposal can also shed light on the findings of Geuden and Sandra (2003), discussed in Yip (in press). In their study of phonemic awareness in Dutch children, they found that young readers were reluctant to split apart a single syllable word at the so-called onset-rime division; instead, they preferred to split apart a word after the vowel and before the final consonant: eg. .....c/at (dispreferred) vs.....ca/t (preferred). This fact can be accounted for if we assume a lack of FOOT in early readers. 


\section{Patricia Schneider-Zioga and Fusa Katada}

\subsection{Suggestive Evidence from Japanese}

It has been claimed that in the English speaking world, ten to twelve percent (10$12 \%$ ) of the population is found to be dyslexic, whereas a much lower four percent (4\%) of the Japanese population is found dyslexic (cf. Sakai 2002). An accurate description of this tendency is that in the Japanese population the problem of phonemic awareness does not surface as much as in the English population. This contrast is often talked about in the Japanese dyslexic literature as being attributable to the contrast between the Japanese transparent orthography, Kana, and the English opaque alphabet. Given that Japanese reading includes Kanji ideographic characters more than the Kana syllabary characters and that Kanji is even more phonologically opaque than the English alphabet (a direct phonological route to reading Kanji is impossible), we suspect that orthographic transparency is not the issue here. Rather we argue that this contrast adds to our proposal in 3.6. Since Japanese is a CV-based language, the Japanese-speaking population does not require a temporal-spatial ordering decision to read materials that are fundamentally CV-based. Therefore, any deficit in this area will remain largely undetected.

\section{Functional Structure}

It is possible to make a different interpretation of Tara's knowledge. Suppose Tara does not completely lack feet. Instead, she attempts to implement a more manageable (least marked) metrical structure, that is, quantity insensitive syllabic feet, by allowing only light syllables, since this allows her to avoid facing temporal spatial ordering decisions.

Alternatively, we might interpret what we are calling a moraic trochee as a functional structure. Suppose that syllabification is driven by functional structure as follows: (i) every mora is CV (in a sense, all languages potentially have quantity insensitive feet), (ii) two moras make up a quantity sensitive unit: [CVCV], (iii) this unit is headed by a functional category $\mathrm{f:}_{\mathrm{f}}[\mathrm{CVCV}]$, (iv) the final $\mathrm{V}$ can be silent according to the context (here right edge of the functional structure) along the lines of van der Hulst's radical CV phonology. A learner who lacks functional categories in this domain cannot construct quantity sensitive units. We note that the role of functional categories in language acquisition is well established. Relevant also is Vergnaud's (2007) claim that the prosodic structure (stress) of words can be interpreted as functional structure. Our findings supports his claim, given he includes footlike structures among the relevant prosodic structures.

\section{Conclusion}

Developmental dyslexia as a phonologically-based disorder has been primarily explored in the literature as a deficit in phonological awareness. Here we have attempted to establish that the core problem does not lie in phonemic awareness. Instead, we argue that it lies in prosodic development, which leads the person 


\section{Phonological Structure in Syllabification}

with dyslexia to not exploit the unit rime in reading. Since reading English requires the construct rime for accurate decoding, the person with dyslexia will read English slowly and inaccurately.

\section{References}

Cassady, Jerrell C. and Lawrence L. Smith. 2004. Acquisition Of Blending Skills: Comparisons Among Body-Coda, Onset-Rime, And Phoneme Blending Tasks. Reading Psychology 25(4): 261 - 272.

Duncan, Lynne G., Phillip H.K. Seymour, and Shirley Hill. 1997. How Important Are Rhyme and Analogy in Beginning Reading? Cognition 63:171-208.

Geudens, Astrid and Dominiek Sandra. 2003. Beyond Implicit Phonological Knowledge: No Support for an Onset-Rime Structure in Children's Explicit Phonological Awareness. Journal of Memory and Language 49:157-182.

Goad, Heather and Kathleen Brannen. 2003. Phonetic Evidence for Phonological Structure in Syllabification. In Jeroen van de Weider, Vincent J. van Heuven and Harry van der Hulst, eds., The Phonological Spectrum, 3-30. Amsterdam: John Benjamins.

Goswami, Usha. 1999. Causal Connections in Beginning Reading: the Importance of Rhyme. Journal of Research in Reading 22 (3):217-240.

Goswami, Usha. 2001. Rhymes Are Important: A Comment on Savage. Journal of Research in Reading 24(1):19-29.

Goswami, Usha, Jennifer Thomson, Ulla Richardson, Rhona Stainthorp, Diana Hughes, Stuart Rosen and Sophie K. Scott. 2002. Amplitude Envelop Onsets and Developmental Dyslexia: A New Hypothesis. Proceedings of the National Academy of Sciences 99(16):10911-10916.

Goswami, Usha. 2003. Why Theories of Dyslexia Require Developmental Designs. Trend in Cognitive Sciences 7:534-554.

Goswami, Usha. 2003. How to Beat Dyslexia: The Broadbent Lecture 2003. The Psychologist 16(9):462-465.

Katada, Fusa. 1990. On the Representation of Moras: Evidence from a Language Game. Linguistic Inquiry 21:641-646.

Kessler, Brett and Rebecca Treiman. 1997. Syllable Structure and the Distribution of Phonemes in English Syllables. The Journal of Memory and Language 37, 295-311.

Kubozono, Haruo. 1989. The Mora and Syllable Structure in Japanese: Evidence from Speech Errors. Language and Speech 32:249-278.

Lowenstamm, Jean. 1996. CV as the Only Syllable Type. In Jacques Durand and Bernard Laks, eds., Current Trends in Phonology: Models and Methods, 419442. European Studies Research Institute, University of Salford Publications.

Sakai, Kuniyoshi. 2002. Gengo-no noukagaku (Brain science of language). Tokyo: ChuouKouronsha. 


\section{Patricia Schneider-Zioga and Fusa Katada}

Thomson, Jennifer, Ben Fryer, James Maltby, and Usha Goswami. 2006. Auditory and motor rhythm awareness in adults with dyslexia. Journal of Research in Reading 29(3):334-348.

Treiman, Rebecca, John Mullennix, Ranka Bijeljac-Babic, and E. Daylene Richmond-Welty. 1995. The Special Role of Rimes in the Description, Use, and Acquisition of English Orthography. Journal of Experimental Psychology: General 124 (2): 107-136.

Vellutino, Frank R. 1979. Dyslexia: Theory and Research. Cambridge, MA: MIT Press.

Wise, Barbara, Richard Olson, and Rebecca Treiman. 1990. Sub-Syllabic Units as Aids in Beginning Readers Word Learning Onset-Rime versus Post-Vowel Segmentation. Journal of Experimental Child Psychology 49:1-19.

Vergnaud, Jean-Roger. 2007. Some Preliminary Remarks on the Syntactic Organization of Phonology. Paper presented at CUNY Phonology Forum 2007.

Yip, Moira. In press. The Non-Existence of the Onset-Rime Boundary. Lingua.

Patricia Schneider-Zioga

CSU Fullerton

Department of English, Comparative Literature, and Linguistics

800 N. State College Blvd.

Fullerton, CA 92834-9480

pzioga@fullerton.edu

Fusa Katada

Waseda University

Faculty of Science and Engineering

Center for English Language Education in Science and Engineering

3-4-1 Okubo, Shinjuku-ku

Tokyo, Japan 169-8555

katada@waseda.jp 